\title{
Study of the management of suspected cardiac infarction by British immediate care doctors
}

\author{
D C RAWLINS
}

\begin{abstract}
A study of the management by immediate care general practitioners of $\mathbf{5 1 1}$ patients suspected of suffering from acute myocardial infarction showed that the median time of arrival after the onset of chest pains was 60.2 minutes. One hundred and eleven patients died of cardiac infarction within 48 hours of the onset of chest pain; 23 died in the presence of the general practitioner.
\end{abstract}

\section{Introduction}

Immediate care schemes are groups of doctors who work in association with the police, fire, and ambulance services to try to provide immediate medical care at the site of an accident or sudden illness. The doctors in these schemes are used to responding rapidly to emergency calls and are equipped to give immediate aid. They have laryngoscopes, endotracheal tubes, suckers, and infusion apparatus; but they do not usually have defibrillators.

The British Association of Immediate Care Schemes was asked to evaluate the use of an antiarrhythmic drug in the early stages of myocardial infarction and as a first step decided to investigate the feasibility and potential value of such a study. This report of the preliminary investigation describes the frequency of emergency calls by patients with chest pain and the sequence of events when general practitioners respond to such calls.

British Association for Immediate Care Scheme, London SW7 1PU D C RAWLINS, $\mathrm{MB}$, BS, honorary secretary and general practitioner, Somerset

\section{Method}

All 1200 general practitioners known to be associated with immediate care schemes in Britain were asked to join in the survey; 423 agreed. They provided details of patients who made an emergency call with chest pain as the primary symptom and who were thought clinically to have had a cardiac infarction, were under the age of 70 , and were seen within 24 hours of the onset of chest pain. Patients who had died before the doctor was called were included.

In the evaluation of results the World Health Organisation criteria ${ }^{1}$ of cardiac infarction were used to classify patients as having had a definite cardiac infarction, a probable cardiac infarction, or a diagnosis other than cardiac infarction; patients in whom there was insufficient evidence for a firm diagnosis were classified separately.

\section{Results}

From 1 December 1978 to 1 January 1980160 general practitioners reported details of 511 patients. The doctors covered a population of 344000 patients, and the incidence was thus $1 \cdot 49 / 1000 /$ year. The patients' ages ranged from 29 to 70 years (mean 57.8 ) and $77.5 \%$ were men. Fifty general practitioners reported only one case and 40 only two.

Clinical investigation and, where applicable, necropsy evidence showed that 247 of the 511 patients had definite and 117 probable cardiac infarction. Fifty-eight patients were found to be suffering from other diseases. In 92 cases the data were insufficient for accurate diagnosis and 29 of these died; they are included in the analysis as "suspected" myocardial infarctions.

The median time from the onset of chest pain to the arrival of the general practitioner was $60 \cdot 2$ minutes; $52 \%$ of patients were seen within one hour (table I).

The treatment given varied. Heroin, morphine, or pethidine was given to 278 patients $(60 \%)$ and other analgesics to $42(9 \%)$. Heroin was the drug of first choice, being used for nearly half of all patients given analgesics. Patients not given analgesics included those who were dead or unconscious when the doctor arrived $(59,12 \%)$ and those whose pain had resolved spontaneously. Among the patients seen 12 
TABLE I-Delay to arrival of GP after onset of chest pain

\begin{tabular}{lcc}
\hline Time & No of patients & Cumulative frequency $(\%)$ \\
\hline $15 \min$ & 86 & $17 \cdot 2$ \\
$155-30(\mathrm{~min})$ & 82 & 33.6 \\
$30-60(\mathrm{~min})$ & 93 & $52 \cdot 2$ \\
$1-2(\mathrm{hr})$ & 76 & 67.4 \\
$2-4(\mathrm{hr})$ & 58 & 79.0 \\
$4-6(\mathrm{hr})$ & 35 & 86.0 \\
$6-12(\mathrm{hr})$ & 45 & $95 \cdot 0$ \\
$>12-18(\mathrm{hr})$ & 15 & 98.0 \\
$18-24(\mathrm{hr})$ & 9 & 100.0 \\
\hline
\end{tabular}

or more hours after the onset of chest pain (24 in total), half received no analgesics.

Sixty-one patients $(13 \%)$ were given antiarrhythmic drugs: 20 received lignocaine and 24 beta-blockers. One hundred and six, however, were already on beta-blockers and had taken a dose in the past 24 hours; and 30 were taking digoxin.

\section{DEATHS}

One hundred and eleven patients died of cardiac infarction within 48 hours of the onset of chest pain- $-31 \%$ of the patients in whom a diagnosis of definite infarction was made. Forty-nine died before the general practitioner's arrival, the median time to death being 10 minutes from the onset of chest pain. A further 23 died while the general practitioner was present and five more en route to hospital. Table II shows time from onset of chest pain to death; 31 occurred within 15 minutes and 49 within one hour. The death rate rose with the age of the patients (table III).

TABLE II-Time from onset of chest pain to death

\begin{tabular}{|c|c|c|}
\hline Time & No of patients & Cumulative frequency $(\%)$ \\
\hline $\begin{array}{l}\leqslant 15(\mathrm{~min}) \\
>15-30(\mathrm{~min}) \\
\geqslant 30-60(\mathrm{~min}) \\
\geqslant 1-2(\mathrm{hr}) \\
\geqslant 2-4(\mathrm{hr}) \\
\geqslant 4-6(\mathrm{hr}) \\
\geqslant 6-12(\mathrm{hr}) \\
\geqslant 12-24(\mathrm{hr}) \\
>24-48(\mathrm{hr})\end{array}$ & $\begin{array}{r}31 \\
6 \\
12 \\
9 \\
10 \\
5 \\
8 \\
12 \\
10\end{array}$ & $\begin{array}{r}30 \cdot 1 \\
35 \cdot 9 \\
47 \cdot 6 \\
56 \cdot 3 \\
66 \cdot 0 \\
70 \cdot 9 \\
78 \cdot 6 \\
90 \cdot 3 \\
100 \cdot 0\end{array}$ \\
\hline$>24-48(\mathrm{hr})$ & 103 & \\
\hline
\end{tabular}

Timing not available for eight patients.

TABLE III-Death rate and age of patients

\begin{tabular}{lccc}
\hline Age & No died & $\begin{array}{c}\text { Total No of } \\
\text { patients }\end{array}$ & $\begin{array}{c}\text { Percentage died in } \\
\text { each age group }\end{array}$ \\
\hline 550 & 15 & 82 & $18 \cdot 3$ \\
$51-60$ & 40 & 173 & $23 \cdot 1$ \\
$61-70$ & 56 & 198 & $28 \cdot 3$
\end{tabular}

TABLE IV-Time of death after arrival of GP (48 died before GP's arrival)

\begin{tabular}{lcc}
\hline Time & No of patients & Cumulative percentage \\
\hline $30(\mathrm{~min})$ & 13 & $21 \cdot 3$ \\
$30-60(\mathrm{~min})$ & 11 & $39 \cdot 3$ \\
$>1-2(\mathrm{hr})$ & 6 & $49 \cdot 1$ \\
$>2-4(\mathrm{hr})$ & 4 & $55 \cdot 7$ \\
$>4-6(\mathrm{hr})$ & 4 & $62 \cdot 3$ \\
$>6-8(\mathrm{hr})$ & 2 & $65 \cdot 6$ \\
$>8-12(\mathrm{hr})$ & 3 & $70 \cdot 5$ \\
$>12-16(\mathrm{hr})$ & 4 & $77 \cdot 1$ \\
$>16-20(\mathrm{hr})$ & 4 & $83 \cdot 7$ \\
$>20-24(\mathrm{hr})$ & 1 & $85 \cdot 3$ \\
$>24-30(\mathrm{hr})$ & 2 & $90 \cdot 2$ \\
$>30-36(\mathrm{hr})$ & 1 & $93 \cdot 5$ \\
$>36-42(\mathrm{hr})$ & 3 & $95 \cdot 1$ \\
$>42-48(\mathrm{hr})$ & 61 & $100 \cdot 0$ \\
\hline & & \\
\hline
\end{tabular}

Table IV shows the time of death in relation to the arrival of the general practitioner. Thirty-six patients died after he had decided on management, given treatment, and left: $8 \cdot 8 \%$ of those kept at home and $8.7 \%$ of those treated in hospital died.

TABLE V-Mean distance (miles) to district general hospital

\begin{tabular}{lcccccccc}
\hline & $0-5$ & $6-10$ & $11-15$ & $16-20$ & $21-25$ & $26-30$ & $31-35$ & $36-40$ \\
\hline $\begin{array}{l}\text { "oin of } \\
\text { patients }\end{array}$ & $11 \cdot 4$ & $29 \cdot 8$ & $25 \cdot 4$ & $15 \cdot 6$ & $5 \cdot 4$ & $5 \cdot 4$ & 6.1 & 0.9
\end{tabular}

\section{PLACE OF TREATMENT}

Of the 434 patients who lived long enough for a decision to be made on place of treatment, $160(39 \%)$ were treated at home, $50(11 \%)$ in general-practitioner hospitals, and the remaining $224(49 \%)$ in district general hospitals. Of the 224 admitted to hospital, $152(67.5 \%)$ were treated in a coronary care unit; but seven of the 13 general-practitioner hospitals had monitoring facilities in use.

\section{TRANSPORT}

Virtually all (153 out of 160) patients treated at home were at home when first seen. The others travelled by private car. A cardiac ambulance was used to transport 12 of the 264 patients treated in hospitals, 14 travelled by private car and the rest by an ordinary ambulance. All patients with a pulse rate below 40 and all those with diastolic blood

TABLE VI-Time from onset of chest pain to hospital admission

\begin{tabular}{lcc}
\hline Time & No of patients & Cumulative percentage \\
\hline $15(\min )$ & 4 & $1 \cdot 6$ \\
$>15-30(\mathrm{~min})$ & 2 & $2 \cdot 4$ \\
$30-60(\mathrm{~min})$ & 26 & 12.5 \\
$>1-2(\mathrm{hr})$ & 67 & $38 \cdot 6$ \\
$2-4(\mathrm{hr})$ & 63 & $63 \cdot 1$ \\
$>4-6(\mathrm{hr})$ & 35 & 76.7 \\
$>6-12(\mathrm{hr})$ & 35 & $90 \cdot 3$ \\
$>12-24(\mathrm{hr})$ & 13 & $95 \cdot 3$ \\
$24-48(\mathrm{hr})$ & 12 & $100 \cdot 0$ \\
\hline
\end{tabular}

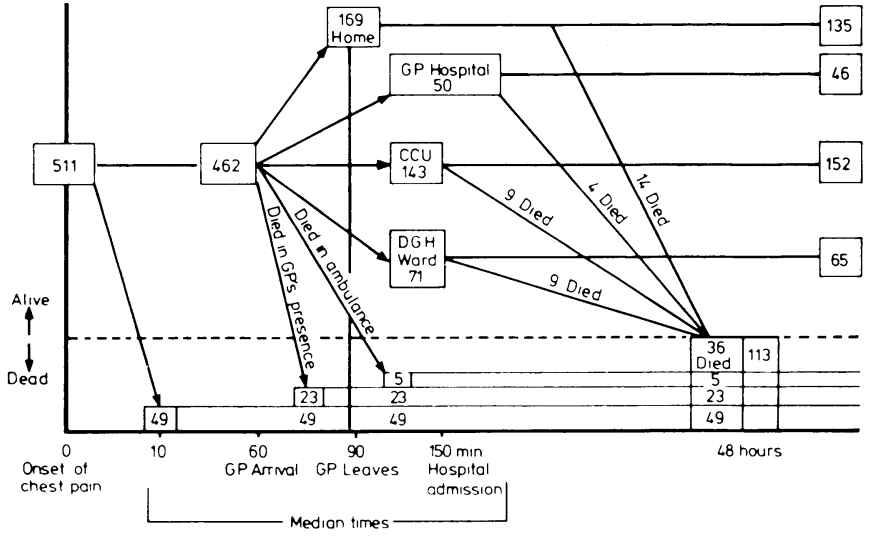

Management of chest pain. Fate of patients from onset of symptoms to 48 hours. Of 511 patients, 55 were not coronaries and 456 probably were.

pressure below $40 \mathrm{~mm} \mathrm{Hg}$ were admitted. The younger the patient, the more likely he was to be admitted to a coronary care unit; $41.7 \%$ of patients under 40 were treated in a coronary care unit but only $23.3 \%$ of those aged 61-70. Table VI shows the delay between the onset of pain and admission to hospital. Only $39 \%$ of patients were admitted in under two hours.

The figure is a diagramatic representation of the results.

.

.




\section{Discussion}

This study is, so far as we know, the only attempt on a nationwide basis in Britain to look at the initial management of patients with chest pain suspected of being due to cardiac infarction. The investigation began as a study of the feasibility of evaluating an antiarrhythmic drug, so the general practitioners and practices were self-selected, and there was no attempt to obtain a randomly selected sample.

In contrast with those in previous surveys, this group of general practitioners reached the patients soon, sometimes very soon, after the onset of their chest pain. We did not record the time the patients asked for help but noted only the interval between the onset of chest pain and the doctor's arrival. Two factors probably combined to reduce this interval: patients and the public in general are becoming aware of the significance of chest pain and are not inhibited from calling for help; and general practitioners, their staff, and their families now recognise suspected cardiac infarction as an emergency and the doctor is called rapidly.

Analgesic drugs were given by general practitioners to $64 \%$ of the patients. Indeed, if we exclude unconscious patients, those who died very soon after the general practitioner arrived, and those no longer in pain, we find that almost all of those requiring pain relief were given analgesics. This finding contrasts with the Glasgow study, ${ }^{6}$ in which only $30 \%$ were reported as having had analgesics.

The death rate is similar to that in previous studies. In 23 cases the general practitioner was present when the patient died, suggesting a substantial potential for preventing death. The patients in this study were attended soon after the onset of chest pain and given conventional treatment, antiarrhythmics being used only occasionally. More effective methods need to be developed and made available to general practitioners who see patients early in the course of myocardial infarction. If every general practitioner had a defibrillator some of the 23 who died might have been resuscitated. Very few general practitioners can own defibrillators at present: the cheapest costs $£ 750$ VAT $=$ $£ 862.50$ (April 1980 prices). An individual general practitioner would see a patient who needed defibrillation only about once every seven years, but if many defibrillators were purchased the price might fall. Forty-one patients died after the departure of the general practitioner or the ambulance, and some of these deaths could have been prevented if a suitable antiarrhythmic agent had been given (if one exists).

Though half the patients were attended within one hour of the onset of chest pain, half were not. This represents a continuing challenge in public education and in improving responses to an often fatal illness-provided that some agent or method for reducing the death rate is found to be effective.

\section{Conclusions and recommendations}

Our study suggests that general practitioners (and possibly doctors in the deputising service) who attend patients with coronaries at times when there is a high possibility that the patient will go into a ventricular fibrillation and die in their presence should be equipped with defibrillators (and be confident in their use). This should be the subject of a further study.

The use of an effective antiarrhythmic drug may similarly have great life-saving potential. Possibly no ideal drug yet exists, but none has been evaluated in early cases (within one hour of onset of chest pain). General practitioners concerned in immediate care would be a suitable group to evaluate possible drugs.

If early treatment is found to be effective the next step is to educate the public to call for help earlier and to ensure that calls are received without delay by a fully equipped doctor who can attend speedily.

We thank Professor Desmond Julian, professor of cardiology, University of Newcastle upon Tyne, for his help, encouragement, and advice; Dr R L Griffiths, Frome, for help in planning the study; Boehringer Ingelheim Ltd for generous financial support and undertaking the statistical analysis; Mrs O Arnison-Newgass for organising the collection of data; Mrs V Baker for secretarial work; and most importantly, all immediate care doctors who reported details of their patients.

Requests for reprints to DCR, Green Farm, Chantry, Frome, Somerset BA11 3LY.

\section{References}

1 World Health Organisation. Ischaemic heart disease register : report on the IVth working group. Copenhagen: WHO Regional Office for Europe, 1970.

2 Pedoe HT, Clayton D, Morris JN, Brigden W, McDonald L. Coronary heart attacks in East London. Lancet 1975; ii :833-8.

${ }^{3}$ Colling A, Dellipiani AW, Donaldson RJ, MacCormack P. Teeside coronary survey. An epidemiological study of acute attacks on myocardial infarction. $\mathrm{Br}$ Med $\mathcal{F}$ 1976;ii:1169-72.

4 Armstrong A, Duncan B, Oliver MF, et al. Natural history of acute coronary heart attacks. Br Heart $\mathcal{f} 1972 ; 34: 67-80$.

5 Kilen LJ. Incidence and presentation of myocardial infarction in an English community. Br Heart $\mathcal{f} 1973 ; 35: 616-22$.

${ }^{6}$ Dunn FG, Elms S, Melville DI, Lawrie TDV, Murray TS. Early treatment of myocardial infarction in the community. $\mathrm{Br}$ Med $\mathrm{f} 1978$;ii 1143-5.

(Accepted 13 March 1981)

\section{What is the risk of amniocentesis? Can it cause a miscarriage?}

Three multicentre case-control trials-one British, one American, and one Canadian-have produced different answers to this question. According to the American ${ }^{1}$ and Canadian studies amniocentesis does not cause increased fetal loss, but the British study ${ }^{2}$ (which looked at 2428 patients between 1973 and 1976) found a $1 \cdot 0-1 \cdot 5 \%$ increased risk of fetal loss and a $1 \cdot 0-1 \cdot 5 \%$ risk of other problems, including severe antepartum haemorrhage, rhesus isoimmunisation, respiratory difficulties at birth, and postural deformities, such as talipes equinovarus - the latter two possibly caused by a continuing leak of amniotic fluid after puncture of the membranes. This disparity in results between the two sides of the Atlantic caused controversy over the design of the studies, none of which was perfect. Perhaps in the 1980s the widespread use of ultrasound guidance in amniocentesis may make the procedure safer than it was in the 1970s, but this remains to be proved. A recent controlled Swedish study ${ }^{3}$ showed a $2.3 \%$ fetal loss rate (from miscarriage and perinatal death), which is similar to (or better than) the control groups in previous studies. In counselling it seems reasonable to put the risk of amniocentesis at about $1 \%$ : thus in older women worried about Down's syndrome the procedure is justified over the age of 40 (when the risk of an affected baby is well over $1 \%$ ) but between 35 and 40 the risks of the procedure balance the risk of having an affected baby. The decision over amniocentesis, however, is influenced by other factors besides the arithmetical odds.

\section{NICHD. National Registry for Amniocentesis Study Group. Midtrimester amniocentesis for prenatal diagnosis: safety and accuracy. $\mathcal{F} A M A$ 1976;236: amniocente. \\ $=$ MRC Working Party on Amniocentesis. An assessment of the hazards of amnio- \\ centesis. Br $\mathcal{f}$ Obstet Gynaecol 1978;85, suppl 2:1-41.
Bartsch FK, Lundberg J, Wahlstrom J. One thousand consecutive midtrimester amniocenteses. Obstet Gynecol 1980;55:305-8.}

Is it true that a cat can smother and kill a baby in its cot, or is this an old wives' tale?

I think that it is probably an old wives' tale. Theoretically it could happen, but one physician with experience of about 3000 cases of sudden deaths in infancy reported no cases of an infant smothered by a cat (personal communication). 